\title{
A Fractal Model for Predicting the Relative Permeability of Rough-Walled Fractures
}

\author{
Zuyang Ye $\mathbb{D})^{1,2}$ Wang Luo, ${ }^{1,2}$ Shibing Huang $\mathbb{D}^{1,2}$ Yuting Chen, ${ }^{3}$ and Aiping Cheng ${ }^{1,2}$ \\ ${ }^{1}$ School of Resource and Environmental Engineering, Wuhan University of Science and Technology, Wuhan 430081, China \\ ${ }^{2}$ Hubei Key Laboratory for Efficient Utilization and Agglomeration of Metallurgic Mineral Resources, \\ Wuhan University of Science and Technology, Wuhan 430081, China \\ ${ }^{3}$ Changjiang Survey, Planning, Design and Research Co., Ltd., Wuhan 430010, China
}

Correspondence should be addressed to Shibing Huang; huangshibing@wust.edu.cn

Received 24 October 2020; Revised 23 November 2020; Accepted 5 March 2021; Published 19 March 2021

Academic Editor: Jian Ji

Copyright (c) 2021 Zuyang Ye et al. This is an open access article distributed under the Creative Commons Attribution License, which permits unrestricted use, distribution, and reproduction in any medium, provided the original work is properly cited.

\begin{abstract}
The relative permeability and saturation relationships through fractures are fundamental for modeling multiphase flow in underground geological fractured formations. In contrast to the traditional straight capillary model from porous media, the realistic flow paths in rough-walled fractures are tortuous. In this study, a fractal relationship between relative permeability and saturation of rough-walled fractures is proposed associated with the fractal characteristics of tortuous parallel capillary plates, which can be generalized to several existing models. Based on the consideration that the aperture distribution of rough-walled fracture can be represented by Gaussian and lognormal distributions, aperture-based expressions between relative permeability and saturation are explicitly derived. The developed relationships are validated by the experimental observations on Gaussian distributed fractures and numerical results on lognormal distributed fractures, respectively.
\end{abstract}

\section{Introduction}

Multiphase flow through fractured media is an important process for a number of practical applications, such as seepage control for rock slope $[1,2]$, petroleum reservoirs [3], nuclear waste disposal [4], and geologic storage of carbon dioxide [5]. In order to understand the influence of multiphase flow behavior in fractured media on implementation with these applications, numerical simulations have been applied in fractured media using a continuum method $[6,7]$ or a discrete fracture network model $[8,9]$. In contrast to the macroscale continuum model, the flow behavior in the fractured rock is mainly governed by the presence of fracture, which can highly improve the permeability of rock masses [10-12]. For the fracture-dominated flow, the relative permeability of a single fracture is one of the key parameters to describe the multiphase flow behavior that controls the accuracy of modeling results during numerical simulations.
In the last decades, multiphase flow behavior in single fractures has been widely investigated through experiments [13-23], numerical simulations [24-28], and theoretical analysis [21, 28-30] by a number of researchers. Several models have been proposed to represent the relative permeability relationships in rough-walled fractures. Romm [13] firstly developed simple linear relationships between relative permeability and saturation for two different phases (water and kerosene) called the $X$ model, but later poor performance was generally observed through other twophase flow experiments [14-16, 20, 21] and numerical analysis $[24,27,28]$ as a result of phase interference. Consequently, Fourar and Lenormand [29] proposed a viscous coupling model by considering significant interference between phases associated with viscosity. However, there is no consensus on the characteristic behavior of relative permeability in rough-walled fractures.

Some well-known models such as the Burdine model [31], Corey model [32], and Brooks and Corey model [33] 
induced from porous media were also borrowed in fitting the relative permeability properties of fractures, according to the conceptualization of rough-walled fractures as two-dimensional porous media. In these conceptual models from porous media, the hypothesis that the flow paths are straight is in contradiction with the actual tortuous flow paths. The tortuosity factor is generally quantified by a power function of function with exponent parameter $m$ and $m=2$ is widely used in Brooks and Corey model [33] while the fitted value $m$ of 1.0 is obtained during Liu et al.'s curve fitting [34]. The physical meaning of the tortuosity factor is still not clear for rough-walled fractures.

When the flow paths are controlled by capillarity during quasistatic displacement, the relative permeability of fracture is substantial influenced by aperture distribution. Some studies $[23,24,27,28]$ have been made to understand the relationships between relative permeability and aperture distribution for rough-walled fractures including numerical approaches for multiphase flow in single fractures, the sensitivity of spatial distribution between apertures on relative permeability predictions, and the determination of empirical parameters related to the residual saturation. However, explicit mathematical relationships between relative permeability and fracture-aperture distribution are still lacking.

A systematic study of relative permeability models with respect to flow tortuosity and its dependence on fractureaperture distribution is a challenging task. Therefore, the primary objectives of this study are (1) to propose a generalized model for relative permeability in rough-walled fractures with consideration of the tortuosity fractal dimension, (2) to develop the relationships between relative permeability and aperture distribution of fractures, and (3) to assess the validity of the proposed model through experimental data and numerical results from the literature.

\section{The Existing Relative Permeability Models}

The relative permeability $\left(k_{r}\right)$ versus saturation $\left(S_{w}\right)$ relationship through rough-walled fractures has been extensively investigated due to their importance in engineering applications. On the observation of two-phase flow between water and kerosene through artificial parallel-plate fractures, Romm [13] presented the $k_{r}-S_{w}$ relationship firstly as a simple linear function:

$$
k_{r}=S_{w}
$$

This linear relationship is also applied to the oil phase, so that the sum of relative permeabilities for water and oil phases was equal to one known as $X$-curve. It is indicated that each phase kept flowing in its self-governed capillary paths without impediment from the other phase.

According to experimental results from the distilled water-nitrogen gas flow through a transparent replica of a natural rock fracture [14], air-water flow in horizontal artificial fractures $[15,18]$, kerosene-water flow in a parallel glass plate fracture [16], nitrogen-water flow in smooth- and rough-walled glass fractures [21], and gas-water flow in an induced fracture from a cylindrical basalt core [20], strong phase interference at the intermediate saturation was found and the relative permeability did not linearly depend on the saturation. Thus, several simple models were established or directly borrowed from porous media to describe the nonlinear behavior of relative permeability.

Based on the porous media approach, the rock fractures are conceptualized as two-dimensional connected porous media. Burdine [31] proposed one of the first theoretical models for $k_{r}-S_{w}$ relationship as

$$
\begin{aligned}
k_{r} & =\frac{\int_{0}^{S_{e}}\left(\mathrm{~d} S_{w e} / P_{c}^{2}\right)}{\int_{0}^{1}\left(\mathrm{~d} S_{w e} / P_{c}^{2}\right)}, \\
S_{w e} & =\frac{S_{w}-S_{w r}}{1-S_{w r}},
\end{aligned}
$$

where $S_{w e}$ and $S_{w r}$ are the effective saturation and residual saturation of the wetting fluid, respectively, and $P_{c}$ is the capillary pressure. Nevertheless, all the capillary tubes in the Burdine model are assumed to be straight along the hydraulic gradient direction. In fact, the flow paths for porous media are quite tortuous. To take into consideration the tortuosity of the capillary tube, an additional tortuosity factor obtained from measured relative permeability data could be approximated as a power function of effective saturation. Then, a new version of the modified Burdine model is given as

$$
k_{r}=S_{w e}^{2} \frac{\int_{0}^{S_{e}}\left(\mathrm{~d} S_{w e} / P_{c}^{2}\right)}{\int_{0}^{1}\left(\mathrm{~d} S_{w e} / P_{c}^{2}\right)} .
$$

The formulation of the Burdine model includes three parameters $S_{w}, S_{w r}$, and $P_{c}$. The relative permeability function is not explicitly expressed within the Burdine model. Once $P_{c}$ as a function of saturation is known, the $k_{r^{-}}$ $S_{w}$ relationship can be derived from equation (4).

Based on the laboratory experiments for a number of soil samples, Corey [32] and Brooks and Corey [33] proposed an empirical relationship between water saturation and capillary pressure in a general form as

$$
S_{w e}=\left(\frac{P_{b}}{P_{c}}\right)^{\lambda},
$$

where $P_{b}$ is the air entry pressure and $\lambda$ is the pore size distribution index. In Corey [32] relation, $\lambda$ is equal to two.

Inserting equation (5) into equation (4) yields

$$
k_{r}=S_{w e}^{((2+3 \lambda) / \lambda)} \text {. }
$$

When $\lambda=2$, equation (6) is equivalent to the Corey model:

$$
k_{r}=S_{w e}^{4}
$$

Brooks and Corey [33] have discussed that media with a wide range of pore size distribution should have small values of $\lambda$. However, media with a uniform pore size could have $\lambda$ 
values close to infinity such as the fractured media; equation (6) can be simplified as

$$
k_{r}=S_{w e}^{3} .
$$

After the observation on several flow structures (bubbles, unstable bubbles, film flow, etc.) for water-air flows in an artificial fracture [15], Fourar and Lenormand [29] developed a viscous coupling model accounting for the coupling between the two fluids flowing simultaneously, whose interface is assumed to be a plane. Based on the pipe-flow model, the wetting phase is in contact with the capillary wall and the nonwetting phase flows in between. The $k_{r}-S_{w}$ function of the water phase is expressed as

$$
k_{r}=\frac{S_{w}^{2}}{2}\left(3-S_{w}\right)
$$

As indicated by Huo and Benson [22] who presented a detailed comparison between the experimental data and existing models of the $k_{r}-S_{w}$ relationship, the $X$-curve could only describe the data from Romm [13]. The Corey model and Brooks and Corey model presented similar results and gave good representations for Chen and Horne's [21] test on randomly rough-walled fractures. The viscous coupling model provided good agreement with the data from Fourar et al. [15] experiment in horizontal artificial fractures and Chen and Horne's [21] on smooth- and homogeneously rough-walled fractures. Some other experimental data $[14,20]$ have a considerable deviation from any of the existing models.

While substantial progress has been made to investigate the relative permeability in rock fractures, there is no general model to predict the $k_{r}-S_{w}$ relationship of a rock fracture. We will develop a reasonable model in this paper and also demonstrate the relationship between the relative permeability and aperture distribution in rough fractures.

\section{Fractal Model of Relative Permeability in Rough-Walled Fractures}

A schematic of parallel capillary plates within a single roughwalled fracture is shown in Figure 1. For simplicity, the water-air two-phase flow through rough-walled fracture is focused on in this study. However, the mechanism and results can be extended to other multiphase flow systems. The flow rate $q$ in a parallel capillary plate within a single fracture is given by cubic law:

$$
q=\frac{b^{3}}{12 \mu} \frac{\Delta P}{L_{t}} \Delta w
$$

where $\Delta P$ is the pressure drop across the parallel capillary plate of length $L_{t}$ (along the flow direction) and aperture $b, \mu$ is the viscosity of water, and $\Delta w$ is the width of the capillary plate.

Based on the Young-Laplace equation, the parallel capillary plate with aperture $b$ is related to the magnitude of capillary pressure $P_{c}$ as

$$
b=\frac{2 T_{s} \cos \alpha}{P_{c}},
$$

where $T_{s}$ is surface tension and $\alpha$ is contact angle.

For a given capillary pressure $P_{c}$, a parallel capillary plate with an aperture equal to or less than $\left(2 T_{s} \cos \alpha /\left|P_{c}\right|\right)$ is generally filled by water and the rest by air. Integrating equation (10) from minimum aperture $b_{\min }$ to the aperture $b$, the total flow rate $Q$ of the entire fracture is given by

$$
Q\left(P_{c}\right)=\int_{b_{\min }}^{b} q \mathrm{~d} N,
$$

where $\mathrm{d} N$ is the number of capillary plates corresponding to aperture $b$ with capillary pressure $P_{c}$.

When the aperture distribution of fracture is defined as a probability density function $f(b)$, inserting equation (10) into equation (12) leads to

$$
\begin{aligned}
Q\left(P_{c}\right) & =\int_{S_{w r}}^{S_{w}} \frac{V \Delta P}{12 \mu} \frac{b^{2}}{L_{t}^{2}} \mathrm{~d} S_{w}, \\
\mathrm{~d} S_{w} & =\frac{b \Delta w L_{t}}{V} \mathrm{~d} N=\frac{b \Delta w L_{t}}{V} f(b) \mathrm{d} b,
\end{aligned}
$$

where $V$ is the total void volume within a single fracture and the residual saturation $S_{w r}$ corresponds to the minimum aperture $b_{\text {min }}$. As water flow is restricted to fracture aperture below the critical aperture $b_{\text {min }}$, the water phase cannot flow in a continuous way and the volume fraction of the immobile water is defined as the residual saturation $S_{w r}$.

In the traditional approaches for developing a closedform relative permeability model in porous media, the circle capillary plates are both assumed to be straight. In reality, the flow paths are generally tortuous based on the experimental observations. The essential assumption of the traditional approaches is that the tortuosity factor is quantified by a power function and the exponent value cannot be determined rigorously in theory, which highly depends on experience from the experimental measurements.

As a result of the geometrical complication of the aperture distribution, the length of the disorder and irregular parallel capillary plate is similar to the measures of coastline, rough surface, mountains, lakes, and islands, which follow the fractal geometry rather than the Euclidean geometry [35]. According to the self-similarity of a fractal capillary plate, the length of a fractal capillary plate can be expressed as

$$
L_{t} \propto \varepsilon^{1-D_{T}},
$$

where $\varepsilon$ is the length scale of measurement.

For the flow through heterogeneous porous media, the tortuous length of the capillary tube is generally calculated by a fractal scaling relationship $L_{t}=\varepsilon^{1-D_{T}} L_{0}^{D_{T}} \quad[36-39]$. Similarly, we argue that the aperture $b$ of parallel capillaries is analogous to the length scale $\varepsilon$. Hence, the length of a capillary plate with aperture $b$ can be rewritten as

$$
L_{t}=b^{1-D_{T}} L_{0}^{D_{T}}
$$




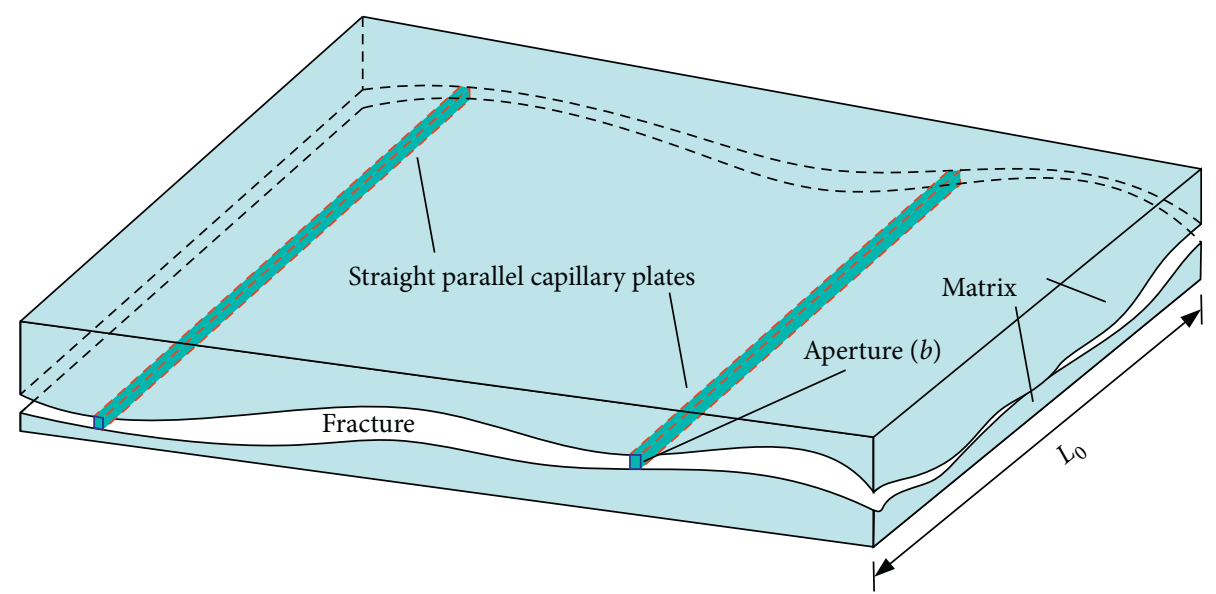

(a)

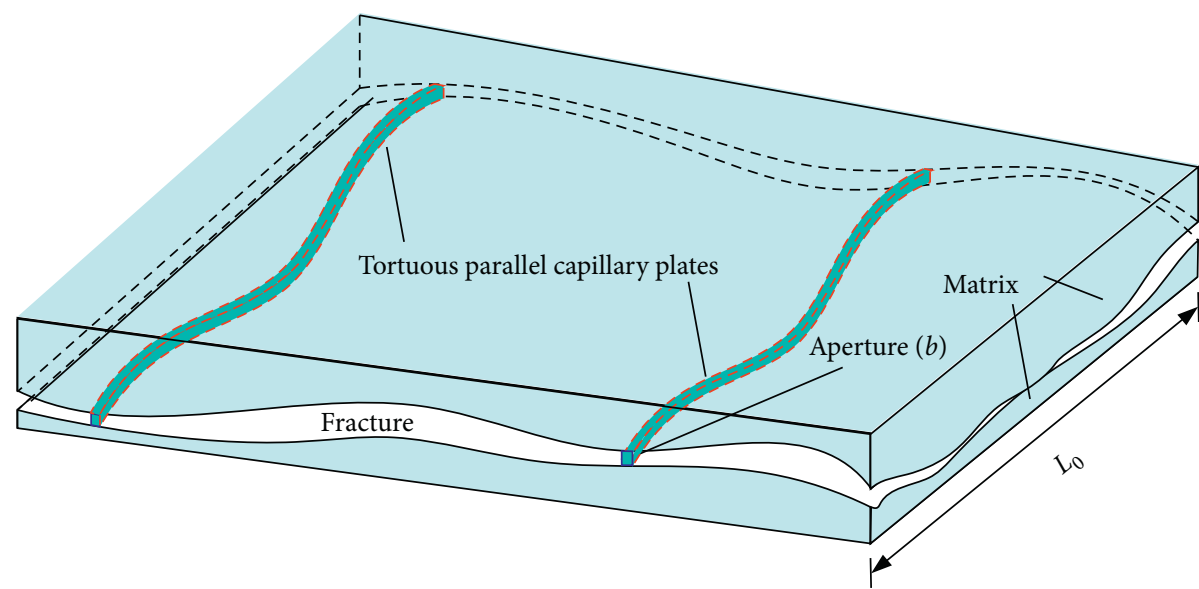

(b)

Figure 1: Schematic of capillary plate flow model with different apertures. (a) The straight parallel capillary model. (b) The tortuous parallel capillary model.

where $D_{T}$ is the fractal dimension of the tortuous parallel capillary plate, $L_{0}$ is the straight distance between inflow and outflow boundaries. For the fractal dimension of tortuous parallel capillary $D_{T}=1, L_{t}$ represents a straight flow path the same as the Burdine model.

Inserting equations (3) and (16) into (13) yields

$$
Q\left(P_{c}\right)=\int_{0}^{S_{w e}} \frac{V \Delta P}{12 \mu} \frac{b^{2 D_{T}}}{L_{0}^{2 D_{T}}} \mathrm{~d} S_{w e}
$$

For a given water-air flow system through a fixed fracture, $\Delta P, V$, and $L_{0}$ are assumed to be constants. By the concept of relative permeability proposed, the relative permeability $k_{r}$ is given as

$$
k_{r}=\frac{Q\left(P_{c}\right)}{Q_{s a}}=\frac{\int_{0}^{S_{w e}} b^{2 D_{T}} \mathrm{~d} S_{w e}}{\int_{0}^{1} b^{2 D_{T}} \mathrm{~d} S_{w e}},
$$

where $Q_{s a}$ is the total flow rate under the saturated condition for the water phase.
Applying the Young-Laplace equation and substituting for $b$ in equation (18) gives

$$
k_{r}=\frac{\int_{0}^{S_{w e}}\left(\mathrm{~d} S_{w e} / P_{c}{ }^{2 D_{T}}\right)}{\int_{0}^{1}\left(\mathrm{~d} S_{w e} / P_{c}{ }^{2 D_{T}}\right)} .
$$

When the tortuosity fractal dimension approaches one with respect to a straight parallel capillary plate, equation (19) can be reduced to the Burdine model equation (2).

Combining equations (5) and (19) gives

$$
k_{r}=S_{w e}^{\left(2 D_{T} / \lambda\right)+1} \text {. }
$$

For $D_{T} / \lambda=0$ when $\lambda \longrightarrow \infty$ in which the unsaturated flow behavior in the rough-walled fracture is approximated to that in porous media with uniform pore size, equation (20) is reduced to the $X$-curve equation (1). For $D_{T} / \lambda=1$, equation (20) is reduced to the Brooks and Corey model equation (8). For $D_{T} / \lambda=1.5$, equation (20) is reduced to the Corey model equation (7). Thus, with one more parameter 
$D_{T}$, equation (20) can capture a relatively large range of the $k_{r}-S_{w}$ relationships as plotted in Figure 2.

\section{The Fractal Relative Permeability for Aperture-Based Fractures}

Based on the Young-Laplace equation (11), equation (19) can also be presented in the form of aperture $b$ :

$$
k_{r}=\frac{\int_{b_{\min }}^{b} b^{2 D_{T}+1} f(b) \mathrm{d} b}{\int_{b_{\min }}^{\infty} b^{2 D_{T}+1} f(b) \mathrm{d} b} .
$$

For the tortuosity fractal dimension $D_{T}=1$, the numerator and denominator of equation (20) indicate the equivalent hydraulic apertures $b_{h}$ and $b_{\text {sat }}$ for unsaturated and saturated fracture, respectively; equation (21) is reduced to Li et al.'s model $k_{r}=\left(b_{h}^{3} / b_{\text {sat }}^{3}\right)$ [30]. Once the probability density function $f(b)$ of aperture distribution is known, the relative permeability can directly be determined from equation (21).

Measurements of aperture distribution from natural and artificial fractures have been performed through numerous measuring techniques including void casting [40], 3D laser/ stereotopometric scanning [41-43], and computed tomography $[22,44,45]$. The measured aperture distributions are supported to be either Gaussian or lognormal. For the sake of completeness, Gaussian and lognormal distribution are both employed to evaluate the relationship between the relative permeability and aperture distribution.

4.1. Normal Distribution-Based Fractures. The Gaussian aperture distribution can be given by the following expression:

$$
f(b)=\frac{1}{\sqrt{2 \pi} \delta} e^{-\left((b-u)^{2} / 2 \delta^{2}\right)}, \quad \text { for } b \geq 0,
$$

where $u$ and $\delta$ are the mean value and standard deviation of the aperture, respectively.

Before presenting the relative permeability relationship with respect to the aperture distribution, it is useful to define a derived integration function:

$$
G(x, y)=\int_{u}^{y} b^{x} \frac{1}{\sqrt{2 \pi} \delta} e^{-\left((b-u)^{2} / 2 \delta^{2}\right)} \mathrm{d} b .
$$

By defining $t=(|b-u| / \sqrt{2} \delta)>0$, the following equation can be obtained:

$$
\begin{aligned}
G(x, y) & =\frac{|y-u|}{y-u} \frac{1}{\sqrt{\pi}} \int_{0}^{t_{y}}(u \pm \sqrt{2} \delta t)^{x} e^{-t^{2}} \mathrm{~d} t, \\
t_{y} & =\frac{|y-u|}{\sqrt{2} \delta}
\end{aligned}
$$

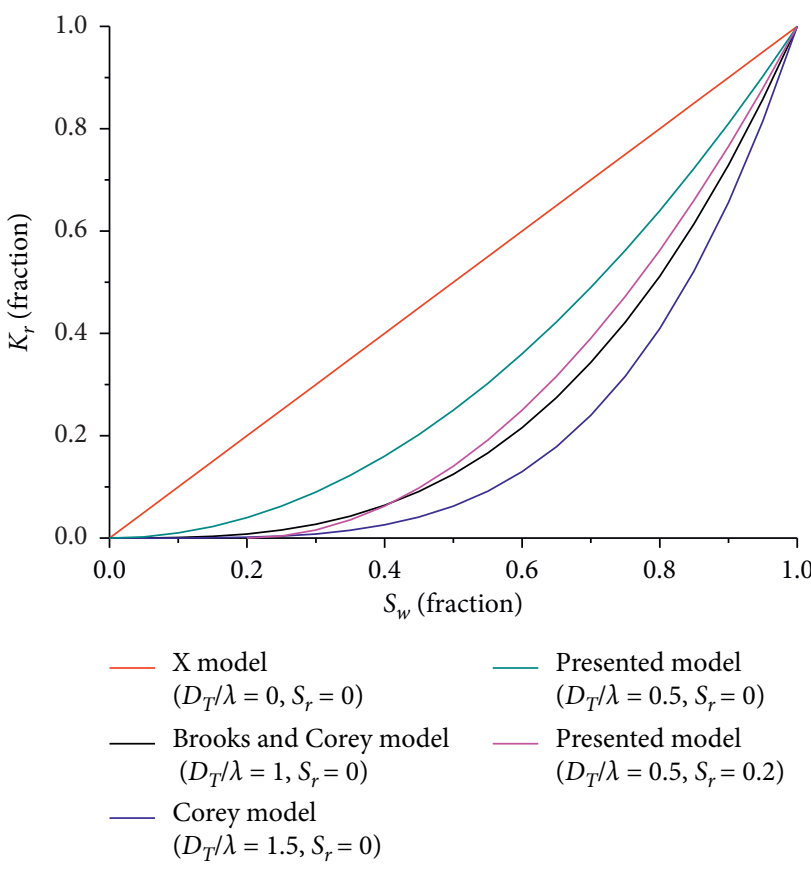

Figure 2: Relationships between relative permeability and saturation calculated from equation (20).

According to Newton's generalized binomial theorem [46], equation (24) can be rewritten as

$$
\begin{aligned}
G(x, y)= & \frac{|y-u|}{y-u} \frac{1}{\sqrt{\pi}} \int_{0}^{t_{y}} \sum_{k=0}^{\infty} C_{y}^{k} u^{x-k}( \pm \sqrt{2} \delta t)^{k} e^{-t^{2}} \mathrm{~d} t \\
= & \frac{|y-u|}{y-u} \frac{1}{\sqrt{\pi}} \sum_{k=0}^{\infty} C_{y}^{k} u^{x-k}( \pm \sqrt{2} \delta)^{k} \int_{0}^{t_{y}} t^{k} e^{-t^{2}} \mathrm{~d} t \\
= & \frac{|y-u|}{y-u} \frac{1}{2 \sqrt{\pi}} \sum_{k=0}^{\infty} C_{y}^{k} u^{x-k}( \pm \sqrt{2} \delta)^{k} \\
& \cdot \int_{0}^{t_{y}}\left(t^{2}\right)^{((k+1) / 2)-1} e^{-t^{2}} \mathrm{~d} t^{2} \\
= & \frac{|y-u|}{y-u} \frac{1}{2 \sqrt{\pi}} \sum_{k=0}^{\infty} C_{y}^{k} u^{x-k}( \pm \sqrt{2} \delta)^{k} \gamma\left(\frac{k+1}{2}, t_{y}^{2}\right),
\end{aligned}
$$

where $\gamma$ refers to Gamma function:

$$
\begin{aligned}
\gamma(x, y) & =\int_{0}^{y} t^{x-1} e^{-t} \mathrm{~d} t, \\
C_{y}^{k} & =\frac{y(y-1) L(y-k+1)}{k !} .
\end{aligned}
$$


A combination of equations (21) and (22) yields and, using equation (26), the relative permeability expression is obtained as

$$
\begin{aligned}
k_{r} & =\frac{\int_{b_{\min }}^{b} b^{2 D_{T}+1}(1 / \sqrt{2 \pi} \delta) e^{-\left((b-u)^{2} / 2 \delta^{2}\right)} \mathrm{d} b}{\int_{b_{\min }}^{\infty} b^{2 D_{T}+1}(1 / \sqrt{2 \pi} \delta) e^{-\left((b-u)^{2} / 2 \delta^{2}\right)} \mathrm{d} b}, \\
& =\frac{\int_{u}^{b} b^{2 D_{T}+1}(1 / \sqrt{2 \pi} \delta) e^{-\left((b-u)^{2} / 2 \delta^{2}\right)} \mathrm{d} b-\int_{u}^{b_{\min }} b^{2 D_{T}+1}(1 / \sqrt{2 \pi} \delta) e^{-\left((b-u)^{2} / 2 \delta^{2}\right)} \mathrm{d} b}{\int_{u}^{\infty} b^{2 D_{T}+1}(1 / \sqrt{2 \pi} \delta) e^{-\left((b-u)^{2} / 2 \delta^{2}\right)} \mathrm{d} b-\int_{u}^{b_{\min }} b^{2 D_{T}+1}(1 / \sqrt{2 \pi} \delta) e^{-\left((b-u)^{2} / 2 \delta^{2}\right)} \mathrm{d} b} \\
& =\frac{G\left(2 D_{T}+1, b\right)-G\left(2 D_{T}+1, b_{\min }\right)}{G\left(2 D_{T}+1, \infty\right)-G\left(2 D_{T}+1, b_{\min }\right)} .
\end{aligned}
$$

For $D_{T}$ is assigned to be zero in mathematics, the water saturation can be calculated as

$$
S_{w}=\frac{\int_{b_{\min }}^{b} b f(b) \mathrm{d} b}{\int_{b_{\min }}^{\infty} b f(b) \mathrm{d} b}=\frac{G(1, b)-G\left(1, b_{\min }\right)}{G(1, \infty)-G\left(1, b_{\min }\right)} .
$$

Relative permeability and saturation equations (28) and (29) based on Gaussian aperture distribution are functions of the parameters $D_{T}$ and $b_{\min }$. Figure 3 illustrates the $k_{r}-S_{w}$ relationships for Gaussian aperturebased fractures with different tortuosity fractal dimensions and minimum apertures. For a Gaussian aperturebased fracture with low $D_{T}$ close to 2 when $b_{\min }$ is kept at zero, the variation of the relative permeability $k_{r}$ versus $S_{w}$ is more pronounced and the relative permeability drops off rather rapidly with increasing $D_{T}$. This is because, for a higher $D_{T}$, a continuous flow path turns to be more tortuous and its component flow rate gets smaller according to the cubic law equation (10).

While the tortuosity fractal dimension $D_{T}$ remains unchanged, with the growth of $b_{\min }$ corresponding to the larger residual saturation, the slope of the $k_{r}-S_{w}$ curves is markedly elevated and the relative permeability decreases considerably. This may be a result of the fact that the number of capillary flow paths is fewer when much more void space is invalid to generate immobile capillary.

4.2. Evaluation of the New Relationship Based on Lognormal Distribution. The lognormal aperture distribution can be given by the following expression:

$$
f(b)=\frac{1}{\sqrt{2 \pi} \delta} e^{-\left((\ln b-u)^{2} / 2 \delta^{2}\right)}, \quad \text { for } b \geq 0 .
$$

Note that $u$ and $\delta$ are the mean value and standard deviation of the logarithm of aperture, respectively.

Similarly, the relative permeability based on the lognormal aperture distribution can be expressed as

$$
k_{r}=\frac{\int_{b_{\min }}^{b} b^{2 D_{T}+1} e^{-\left((\ln b-u)^{2} / 2 \delta^{2}\right)} \mathrm{d} \ln b}{\int_{b_{\min }}^{\infty} b^{2 D_{T}+1} e^{-\left((\ln b-u)^{2} / 2 \delta^{2}\right)} \mathrm{d} \ln b} .
$$

If defining $t=((\ln b-u) / \sqrt{2} \delta)$, the relative permeability and saturation can be derived as

$$
\begin{aligned}
k_{r} & =\frac{\int_{t_{\min }}^{t}\left(e^{\sqrt{2} \delta t+u}\right)^{2 D_{T}+1} e^{-t^{2}} \mathrm{~d} t}{\int_{t_{\min }}^{\infty}\left(e^{\sqrt{2} \delta t+u}\right)^{2 D_{T}+1} e^{-t^{2}} \mathrm{~d} t} \\
& =\frac{\int_{t_{\min }}^{t} e^{-\left[t-\left(\sqrt{2}\left(2 D_{T}+1\right) \delta / 2\right)\right]^{2}} \mathrm{~d} t}{\int_{t_{\min }}^{\infty} e^{-\left[t-\left(\sqrt{2}\left(2 D_{T}+1\right) \delta / 2\right)\right]^{2}} \mathrm{~d} t}=\frac{\operatorname{erf}(\xi)-\operatorname{erf}\left(\xi_{\min }\right)}{1-\operatorname{erf}\left(\xi_{\min }\right)} \\
S_{w} & =\frac{\operatorname{erf}(t-\sqrt{2} \delta / 2)-\operatorname{erf}\left(t_{\min }-\sqrt{2} \delta / 2\right)}{1-\operatorname{erf}\left(t_{\min }-\sqrt{2} \delta / 2\right)} \\
t_{\min } & =\frac{\ln b_{\min }-u}{\sqrt{2} \sigma} ; \\
\xi & =t-\frac{\sqrt{2}\left(2 D_{T}+1\right) \delta}{2} ; \\
\xi_{\min } & =t_{\min }-\frac{\sqrt{2}\left(2 D_{T}+1\right) \delta}{2}
\end{aligned}
$$

Relative permeability and saturation based on lognormal aperture distribution equations (32) and (33) are also a function of the parameters $D_{T}$ and $b_{\text {min }}$. A relatively large range of the $k_{r}-S_{w}$ relationships for lognormal aperturebased fractures with different tortuosity fractal dimensions and minimum apertures is depicted in Figure 4, indicating considerable sensitivity to the tortuosity fractal dimension and minimum aperture. Similar to the relative permeability curves shown in Figure 3, the relative permeability decreases with the increment of $D_{T}$ for a specified $b_{\text {min }}$, while it reduces considerably with the increment of $b_{\text {min }}$ for a specified $D_{T}$. 


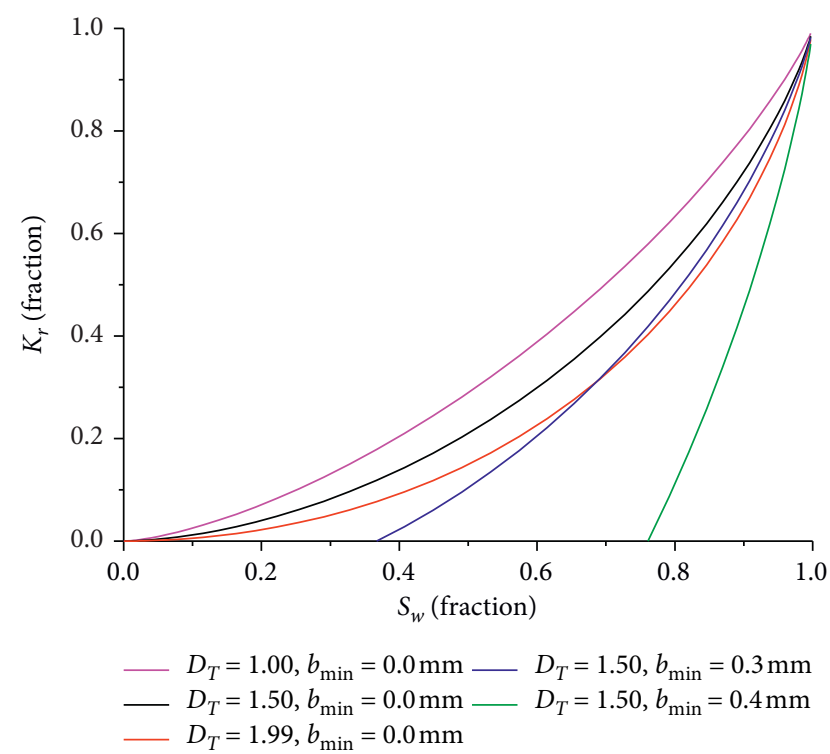

FIGURE 3: Predicted relationships between relative permeability and saturation with different tortuosity fractal dimensions and minimum apertures. The parameters used in equations (28) and (29) are $u=0.3 \mathrm{~mm}$ and $\delta=0.1 \mathrm{~mm}$.

\section{Model Validation and Prediction}

5.1. Experimental Validation against Laboratory Observations. In order to demonstrate the validity of the proposed $k_{r}-S_{W}$ relationships in the form of equations (28) and (29), the comprehensive experimental measurements for the nitrogen-water flow of rough-walled fractures reported by Chen and Horne [21] are applied to be compared with our predictions. The $k_{r}-S_{W}$ data of two analog fractures (homogeneously and randomly rough-walled fractures) with Gaussian aperture distributions are both presented. The statistical parameters for homogeneously and randomly rough-walled fractures are $u=0.145 \mathrm{~mm}$ and $\delta=0.03 \mathrm{~mm}$, and $u=0.24 \mathrm{~mm}$ and $\delta=0.05 \mathrm{~mm}$, respectively.

Figure 5 shows good agreement between the proposed model and the data from Chen and Horne [21]. Based on the least square method, the fitted parameters are $D_{T}=1.75$ and $b_{\min }=0.136 \mathrm{~mm}$ for homogeneously rough-walled fracture and $D_{T}=1.9$ and $b_{\min }=0.24 \mathrm{~mm}$ for randomly rough-walled fracture. The values for the correlation coefficient $\left(R^{2}\right)$ of curve fitting are above 0.95 . The predictions by other models including $X$-model, Brooks and Corey model, and Corey model are also plotted in Figure 4. The Brooks and Corey model gives better results than the $X$ model and Corey model. However, the residual saturation predicted using the Brooks and Corey model is specified as zero and diverges from the actual residual saturation $\left(S_{w r}=0.25\right.$ and 0.39 for homogeneously and randomly rough-walled fractures, resp.) based on the experimental measurements.

Significantly, it is realized that the tortuosity fractal dimension $D_{T}$ of the homogeneously rough-walled fracture is less than that of randomly rough-walled fracture. This can

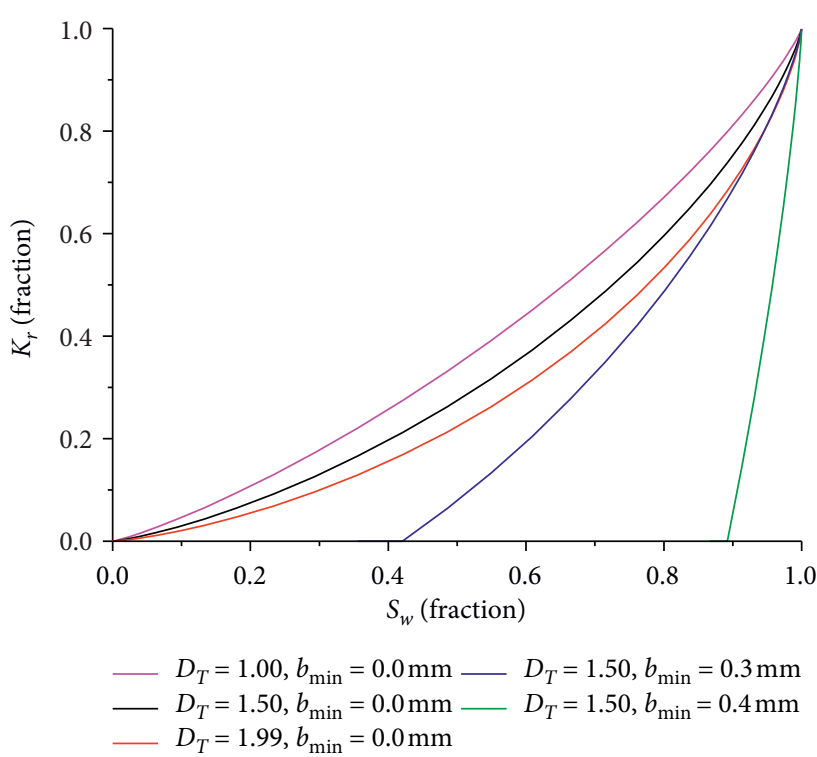

FIgURE 4: Predicted relationships between relative permeability and saturation with different tortuosity fractal dimensions and minimum apertures. The parameters used in equations (32) and (33) are $u=0.3 \mathrm{~mm}$ and $\delta=0.2 \mathrm{~mm}$.

be understood from the characteristics of the Gaussian aperture distribution, in which the aperture variation of the former does not have correlated spatial correlation whereas that of the latter does. Therefore, the flow paths formed in the homogeneously rough-walled fracture are less tortuous corresponding to lower $D_{T}$.

5.2. Comparison with Numerical Solutions. At the present time, there are a few systematic studies on experimental data based on lognormal distributed fracture with which theoretical prediction for fracture relative permeability can be compared. However, Pruess and Tsang [24] have developed a numerical model based on percolation theory to numerically study the two-phase flow properties in fractures with lognormal aperture distributions and the relative permeability data for two typical fractures with the same lognormal aperture distribution $(u=0.0818 \mathrm{~mm}$ and $\delta=0.0043 \mathrm{~mm})$, and different anisotropy of spatial correlation are both calculated by simulating each phase flows separately in their filled void space. Based on a general simulator "MULKOM," the fracture aperture is discretized with $20 \times 20$ grid blocks and a pressure difference is assigned to the inflow and outflow boundaries while the residual boundaries are impermeable.

Figure 6 shows matches between the simulated relative permeability-saturation relations and curves predicted using the proposed model, $X$ model, Corey model, and Brooks and Corey model. For a given saturation, the $X$ model generally overestimates the relative permeability and the Corey model generally underestimates the relative permeability, being in disagreement with the numerical results. The proposed model and Brooks and Corey model are overall closer to the measurements than the $X$ model and Corey model predictions. 


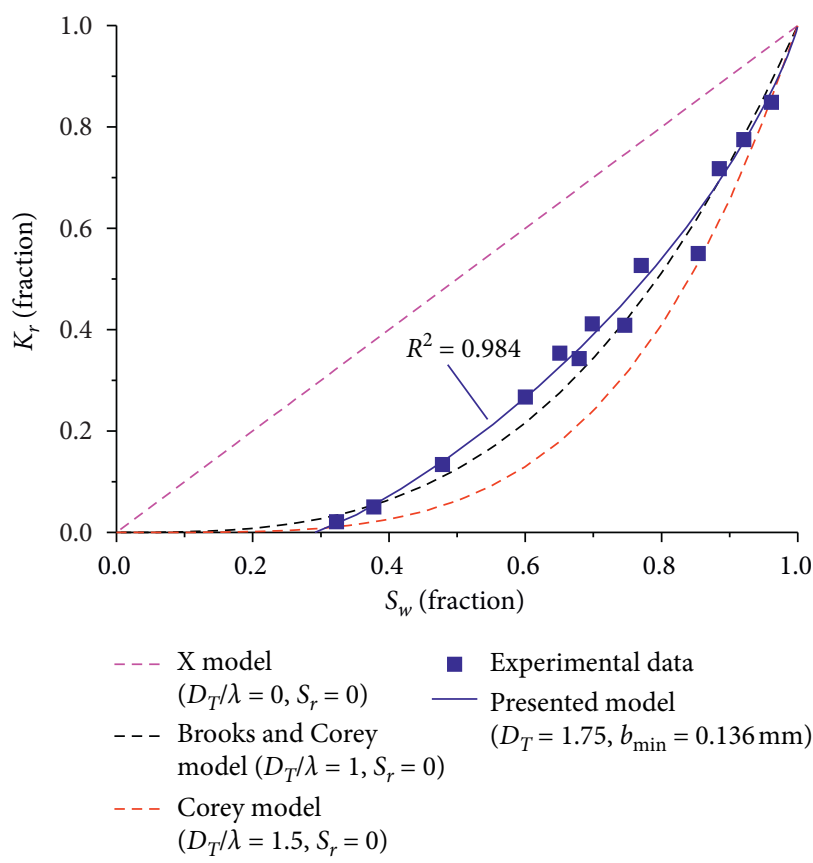

(a)

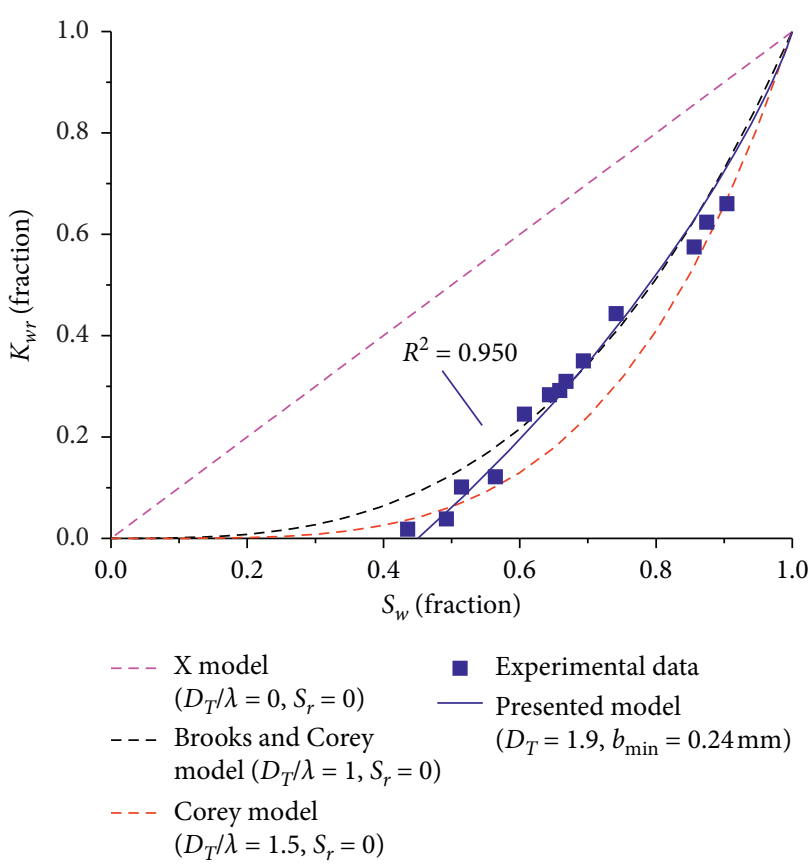

(b)

FIgURE 5: Comparisons of relative permeabilities between the present model and measured data: (a) homogeneously rough with $u=0.145 \mathrm{~mm}$ and $\delta=0.03 \mathrm{~mm}$ and (b) randomly rough with $u=0.24 \mathrm{~mm}$ and $\delta=0.05 \mathrm{~mm}$.

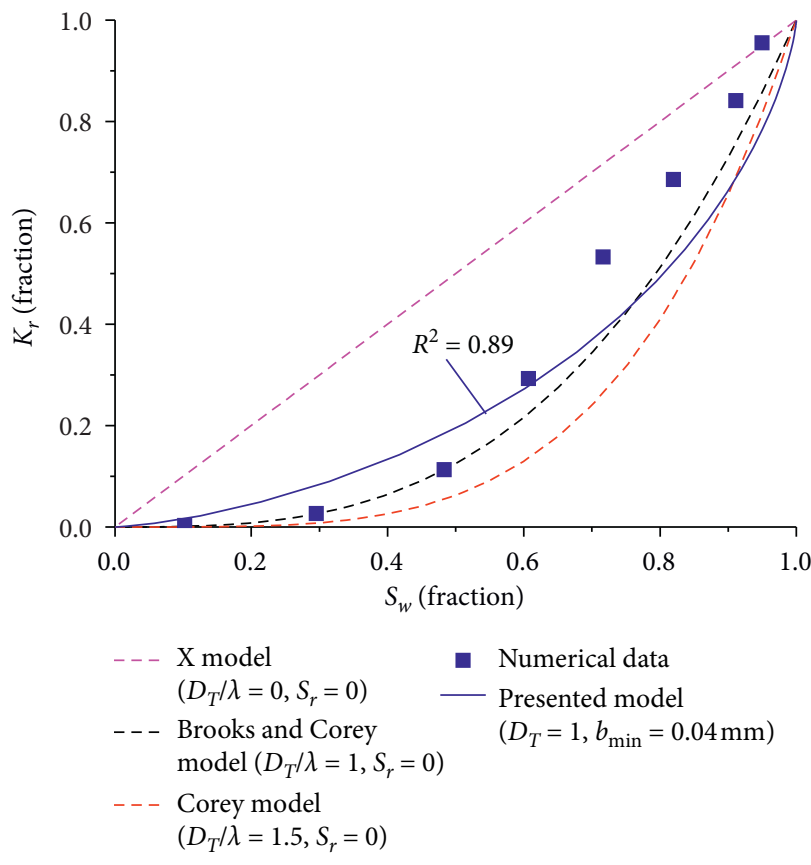

(a)

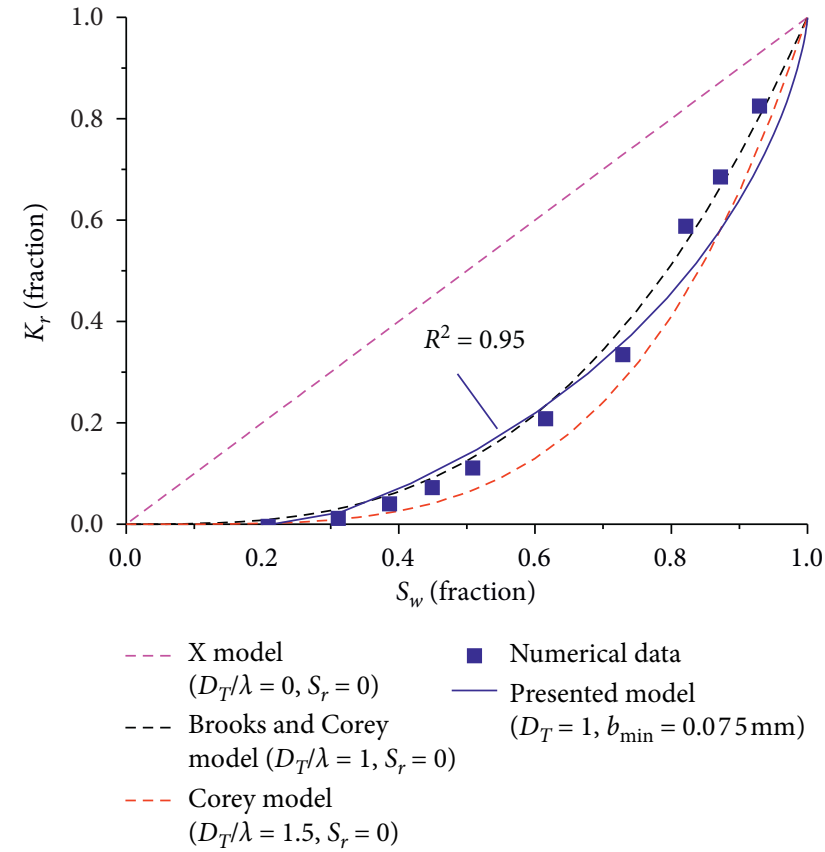

(b)

FIGURE 6: Comparisons of relative permeabilities between the present model and measured data for two fractures of the same lognormal aperture distribution with the mean value and standard deviation of $0.0818 \mathrm{~mm}$ and $0.0043 \mathrm{~mm}$, respectively: (a) isotropic spatial correlation and (b) anisotropic spatial correlation. 
As indicated in Figure 6, some discrepancies between the analytical predictions and numerical results are apparent; for example, relative permeabilities are somewhat too low for large saturations, while, at low saturations, relative permeabilities are somewhat too high. Agreement is rather good at intermediate saturations. Note that the resultant $D_{T}$ values are identical with one, indicating that the flow paths in these two different spatial correlated fractures are close to straight without the influence of anisotropy of aperture distribution. This may be due to the insufficient statistical quantity of aperture elements as mentioned by Pruess and Tsang [24]; each fracture realization includes only 400 aperture elements and lacks the chance to generate tortuous flow paths in large probability.

\section{Conclusions}

The relative permeability in rough-walled fractures is a fundamental parameter in the multiphase flow through fractured media. A fractal model for estimating the relationship between relative permeability and saturation of rough-walled fractures is derived analytically based on the cubic law and the tortuous capillary model. The proposed model has considered the fractal characteristics of tortuous parallel capillary plates and can generalize the primary existing relationship in the literature. Based on the aperture-distributed dependence of relative permeability properties, the relative permeability expressions in the form of aperture with respect to Gaussian and lognormal distribution are both developed explicitly. The predictions of relative permeabilities from the proposed model are shown to be consistent with experimental observations for Gaussian distributed fractures and numerical data for lognormal distributed fracture. The fractal relative permeability model for rough-walled fracture is the terms of the tortuosity fractal dimension, determination of the tortuosity fractal dimension associated with aperture distribution is an interesting and challenging topic, and this work is in processing.

\section{Data Availability}

The data used in the present study may be available upon request from the authors.

\section{Conflicts of Interest}

The authors declare that they have no conflicts of interest regarding the publication of this paper.

\section{Acknowledgments}

The financial support from the National Natural Science Foundation of China (nos. 42077243 and 51709207), Natural Science Foundation of Hubei Province (no. 2018CFB631), and Visiting Researcher Fund Program of State Key Laboratory of Water Resources and Hydropower Engineering Science (2019SGG04) are gratefully acknowledged.

\section{References}

[1] Z. Ye, "Numerical analysis of unsaturated seepage flow in twodimensional fracture networks," International Journal of Geomechanics, vol. 17, no. 5, Article ID 04016118, 2017.

[2] C. Yao, Y. Shao, J. Yang et al., "Effects of non-Darcy flow on heat-flow coupling process in complex fractured rock masses," Journal of Natural Gas Science and Engineering, vol. 83, Article ID 103536, 2020.

[3] Y. Li, Y.-F. Chen, G.-J. Zhang, Y. Liu, and C.-B. Zhou, "A numerical procedure for modeling the seepage field of watersealed underground oil and gas storage caverns," Tunnelling and Underground Space Technology, vol. 66, pp. 56-63, 2017.

[4] H. H. Liu, C. Doughty, and G. S. Bodvarsson, "An active fracture model for unsaturated flow and transport in fractured rocks," Water Resources Research, vol. 34, no. 10, pp. 2633-2646, 1998.

[5] C. Chang, Q. Zhou, M. Oostrom, T. J. Kneafsey, and $\mathrm{H}$. Mehta, "Pore-scale supercritical $\mathrm{CO}_{2}$ dissolution and mass transfer under drainage conditions," Advances in Water Resources, vol. 100, pp. 14-25, 2017.

[6] Z. Ye, Q. Fan, S. Huang, and A. Cheng, "A one-dimensional line element model for transient free surface flow in porous media," Applied Mathematics and Computation, vol. 392, Article ID 125747, 2021.

[7] Z. Ye, H. Qin, Y. Chen, and Q. Fan, “An equivalent pipe network model for free surface flow in porous media," Applied Mathematical Modelling, vol. 87, pp. 389-403, 2020.

[8] Z. Ye, Q. Jiang, C. Yao et al., "The parabolic variational inequalities for variably saturated water flow in heterogeneous fracture networks," Geofluids, vol. 2018, Article ID 9062569, 16 pages, 2018.

[9] F. Xiong, Q. Jiang, C. Xu, X. Zhang, and Q. Zhang, "Influences of connectivity and conductivity on nonlinear flow behaviours through three-dimension discrete fracture networks," Computers and Geotechnics, vol. 107, pp. 128-141, 2019.

[10] C. Yao, Y. Shao, J. Yang et al., "Effects of fracture density, roughness, and percolation of fracture network on heat-flow coupling in hot rock masses with embedded three-dimensional fracture network," Geothermics, vol. 87, Article ID 101846, 2020.

[11] X. Zhang, H. Chen, and C. Yao, "Seepage characteristics of triaxial compression-induced fractured rocks under varying confining pressures," International Journal of Geomechanics, vol. 20, no. 9, Article ID 04020160, 2020.

[12] F. Huang, C. Yao, J. Yang, C. He, Y. Shao, and C. Zhou, "Connectivity evaluation of fracture networks considering the correlation between trace length and aperture," Applied Mathematical Modelling, vol. 88, pp. 870-887, 2020.

[13] E. Romm, Fluid Flow in Fractured Rocks, Nedra Publishing House, Moscow, Russia, 1966.

[14] P. Persoff and K. Pruess, "Two-phase flow visualization and relative permeability measurement in natural rough-walled rock fractures," Water Resources Research, vol. 31, no. 5, pp. 1175-1186, 1995.

[15] M. Fourar, S. Bories, R. Lenormand, and P. Persoff, "Twophase flow in smooth and rough fractures: measurement and correlation by porous-medium and pipe flow models," Water Resources Research, vol. 29, no. 11, pp. 3699-3708, 1993.

[16] D. Pieters and R. Graves, "Fracture relative permeability: linear or non-linear function of saturation," in Proceedings of the 1994 International Petroleum Conference and Exhibition of Mexico, Veracruz, Mexico, October 1994. 
[17] S. Reitsma and B. H. Kueper, "Laboratory measurement of capillary pressure-saturation relationships in a rock fracture," Water Resources Research, vol. 30, no. 4, pp. 865-878, 1994.

[18] S. Huang, Z. Lu, Z. Ye, and Z. Xin, "An elastoplastic model of frost deformation for the porous rock under freeze-thaw," Engineering Geology, vol. 278, Article ID 105820, 2020.

[19] S. B. Huang, Y. H. Ye, X. Z. Cui, A. P. Cheng, and G. F. Liu, "Theoretical and experimental study of the frost heaving characteristics of the saturated sandstone under low temperature," Cold Regions Science and Technology, vol. 174, Article ID 103016, 2020.

[20] S. P. Bertels, D. A. DiCarlo, and M. J. Blunt, "Measurement of aperture distribution, capillary pressure, relative permeability, and in situ saturation in a rock fracture using computed tomography scanning," Water Resources Research, vol. 37, no. 3, pp. 649-662, 2001.

[21] Y. Chen and R. Horne, "Two-phase flow in rough-walled fractures: experiments and a flow structure model," Water Resources Research, vol. 42, no. 3, 2006.

[22] D. Huo and S. M. Benson, "Experimental investigation of stress-dependency of relative permeability in rock fractures," Transport in Porous Media, vol. 113, no. 3, pp. 567-590, 2016.

[23] N. Watanabe, K. Sakurai, T. Ishibashi et al., "New $v$-type relative permeability curves for two-phase flows through subsurface fractures," Water Resources Research, vol. 51, no. 4, pp. 2807-2824, 2015.

[24] K. Pruess and Y. W. Tsang, "On two-phase relative permeability and capillary pressure of rough-walled rock fractures," Water Resources Research, vol. 26, no. 9, pp. 1915-1926, 1990.

[25] R. J. Glass, M. J. Nicholl, and L. Yarrington, "A modified invasion percolation model for low-capillary number immiscible displacements in horizontal rough-walled fractures: influence of local in-plane curvature," Water Resources Research, vol. 34, no. 12, pp. 3215-3234, 1998.

[26] R. Hughes and M. Blunt, "Network modeling of multiphase flow in fractures," Advances in Water Resources, vol. 24, no. 34, pp. 409-421, 2001.

[27] Z. Ye, H.-H. Liu, Q. Jiang, and C. Zhou, "Two-phase flow properties of a horizontal fracture: the effect of aperture distribution," Advances in Water Resources, vol. 76, pp. 43-54, 2015.

[28] Z. Ye, H.-H. Liu, Q. Jiang, Y. Liu, and A. Cheng, "Two-phase flow properties in aperture-based fractures under normal deformation conditions: analytical approach and numerical simulation," Journal of Hydrology, vol. 545, pp. 72-87, 2017.

[29] M. Fourar and R. Lenormand, "A viscous coupling model for relative permeabilities in fractures," in Proceedings of the 1998 SPE Annual Technical Conference and Exhibition, New Orleans, LA, USA, September 1998.

[30] Y. Li, Y.-F. Chen, and C.-B. Zhou, "Hydraulic properties of partially saturated rock fractures subjected to mechanical loading," Engineering Geology, vol. 179, pp. 24-31, 2014.

[31] N. T. Burdine, "Relative permeability calculations from pore size distribution data," Journal of Petroleum Technology, vol. 5, no. 3, pp. 71-78, 1953.

[32] T. Corey, "The interrelation between gas and oil relative permeabilities," Producers Monthly, vol. 19, no. 1, pp. 38-41, 1954.

[33] R. Brooks and A. Corey, "Hydraulic properties of porous media," Hydrology Papers, Colorado State University, Fort Collins, CO, USA, 1964.

[34] H.-H. Liu, M.-Y. Wei, and J. Rutqvist, "Normal-stress dependence of fracture hydraulic properties including two- phase flow properties," Hydrogeology Journal, vol. 21, no. 2, pp. 371-382, 2013.

[35] B. Mandelbrot, The Fractal Geometry of Nature, W.H. Freeman, New York, NY, USA, 1983.

[36] B. Yu and P. Cheng, "A fractal permeability model for bidispersed porous media," International Journal of Heat and Mass Transfer, vol. 45, no. 14, pp. 2983-2993, 2002.

[37] G. Lei, P. C. Dong, S. Y. Mo, S. H. Gai, and Z. S. Wu, "A novel fractal model for two-phase relative permeability in porous media," Fractals, vol. 23, no. 2, Article ID 1550017, 2015.

[38] B. Xiao, X. Zhang, W. Wang et al., "A fractal model for water flow through unsaturated porous rocks," Fractals, vol. 26, no. 2, Article ID 1840015, 2018.

[39] B. Xiao, "Kozeny-Carman constant for gas flow through fibrous porous media by fractal-Monte Carlo simulations," Fractals, vol. 27, 2019.

[40] S. Gentier, D. Billaux, and L. van Vliet, "Laboratory testing of the voids of a fracture," Rock Mechanics and Rock Engineering, vol. 22, no. 2, pp. 149-157, 1989.

[41] F. Xiong, Q. Jiang, Z. Ye, and X. Zhang, "Nonlinear flow behavior through rough-walled rock fractures: the effect of contact area," Computers and Geotechnics, vol. 102, pp. 179195, 2018.

[42] X. Zhang, Q. Jiang, N. Chen, W. Wei, and X. Feng, "Laboratory investigation on shear behavior of rock joints and a new peak shear strength criterion," Rock Mechanics and Rock Engineering, vol. 49, no. 9, pp. 3495-3512, 2016.

[43] Z. C. Tang and Z. Q. Zhang, "Elliptical Hertz-based general closure model for rock joints," Rock Mechanics and Rock Engineering, vol. 54, pp. 477-486, 2020.

[44] Z. C. Tang, Q. Z. Zhang, and J. Peng, "Effect of thermal treatment on the basic friction angle of rock joint," Rock Mechanics and Rock Engineering, vol. 53, no. 4, pp. 1973-1990, 2020.

[45] Z. C. Tang, "Experimental investigation on temperature-dependent shear behaviors of granite discontinuity," Rock Mechanics and Rock Engineering, vol. 53, no. 9, pp. 40434060, 2020.

[46] A. Okounkov, "Binomial formula for MacDonald polynomials and applications," Mathematical Research Letters, vol. 4, no. 4, pp. 533-553, 1997. 